\section{ARTICLE}

Peter Stam and Jessica Coleman Office for National Statistics

\title{
The relationship between hours worked in the UK and the economy
}

\section{Introduction}

Hours of work are recognised by the Office for National Statistics (ONS) and the International Labour Organisation (ILO) as key indicators of the labour market. The difference between actual and usual hours worked may result from firms using overtime to meet increasing demand or reducing hours to control costs, and as such, could be considered an indicator of labour market flexibility.

The Monetary Policy Committee at the Bank of England pay close attention to the number of hours worked when considering monetary policy decisions as these may be more closely related to changes in demand and output than the level of employment. This is because firms might want to retain staff during periods of lower output growth, or conversely delay recruitment until the need for it is clearly established through a sustained increase in demand. This article describes the different measures of hours data in the UK and investigates how they may be used to analyse the UK labour market.
(

lassical labour market theory focuses on the interaction between the demand and supply of labour.

Labour supply reflects individual choices of how much labour to supply at each wage rate. Labour demand reflects the decisions by firms about how much they wish to employ at each wage rate. However, the prevailing wage rate in an economy may not necessarily reconcile labour demand and labour supply. For example, Tam (2010) examined trends in time-related underemployment and overemployment between 2001 and 2010 and found there are often mismatches between workers' actual and preferred number of hours worked. Furthermore, the extent of these mismatches may also be cyclical, as during the 2008-09 recession, underemployment began to rise sharply and overemployment fell.

This article finds that the number of hours worked is a more responsive measure of the state of the labour market than employment. Comparing the number of hours worked to indicators of the wider economy shows that it is likely to be demand from firms which is driving the number of hours, rather than supply from individuals. The analysis also shows that the UK appears to have developed a long working-hours culture relative to the rest of the European Union (EU).

\section{Labour supply}

The standard theory of labour supply is based on the assumption that individuals choose their optimal number of working hours based on a choice of available hours and wages. In a practical sense, labour supply is more complex and is strongly influenced by a number of factors such as wage rates, employer preferences, non-labour income (like that of a spouse), family structure and individual characteristics (Böheim and Taylor, 2003; Antonazzo et al, 2003). According to Adam's 'equity theory', employees seek to maintain equity between the input they bring to a job (effort, skills, personal sacrifice) and the outcomes they receive (Adams, 1963). For example, a working mother may accept a lower wage in return for more flexible working hours.

\section{Labour demand}

Labour demand is conventionally treated as a 'derived' demand - that is, labour is not demanded by firms for itself but for the goods and services it produces. Therefore, employers' demand for labour is typically measured through jobs, vacancies and hours worked. The statistical picture of labour demand is complicated as employers may fill vacancies with people who have more than one job, either with them or with another employer, or with people who share the same job.

Firms are thought to vary their labour input in the short-term in line with changing demand. Other inputs, such as capital, are assumed to be fixed in the short-term and can only be varied through long-term changes in investment. Varying labour through recruitment or redundancy, 


\section{Figure 1}

\section{Total hours and employment level, ${ }^{1} 1971$ to 2010}

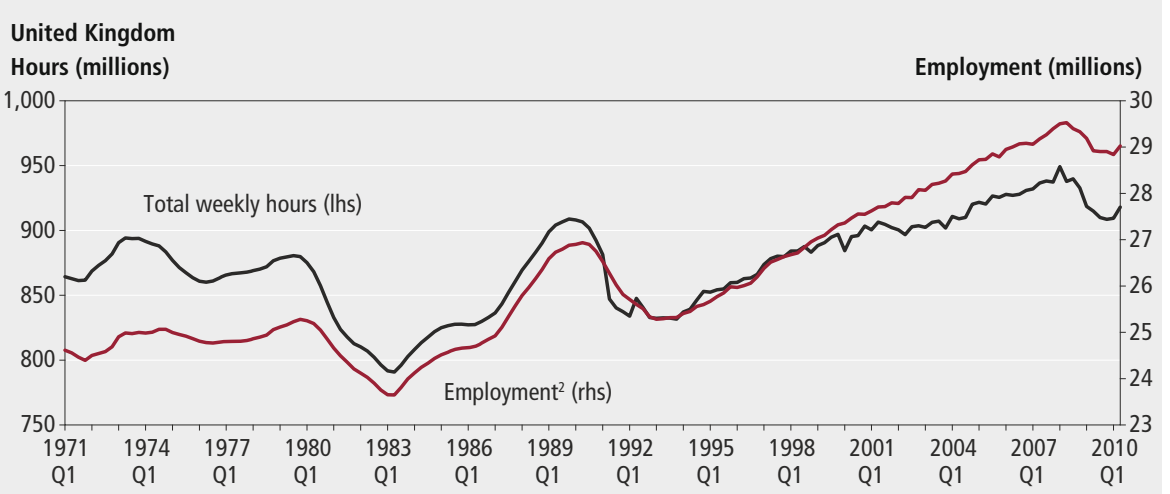

Notes:

1 Both time series are seasonally adjusted.

Source: Labour Force Survey

2 All aged 16 and over.

Figure 2

\section{Average weekly hours of work and total number of people in full-time and part-time employment, ${ }^{1} 1993$ to 2010}

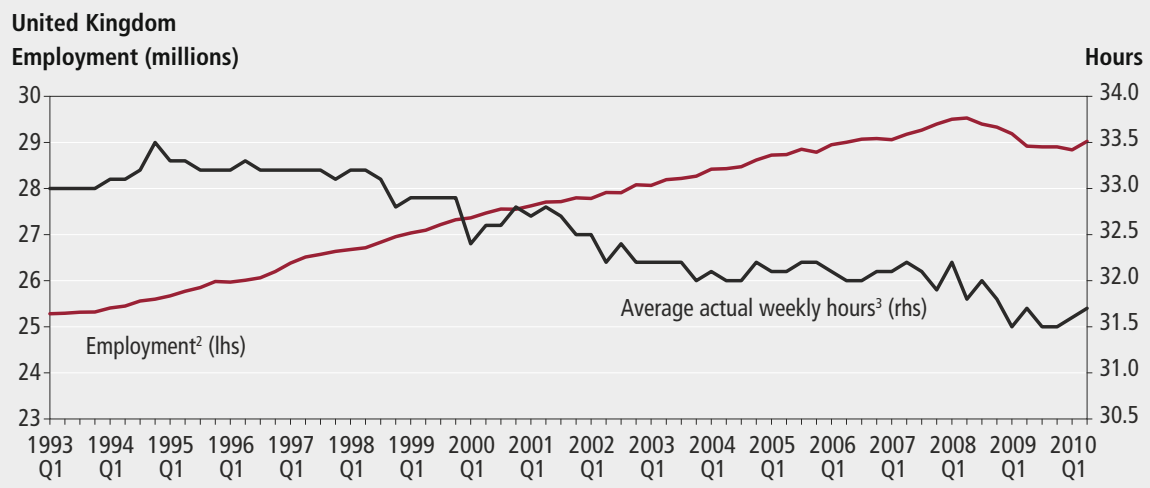

\section{Notes:}

Source: Labour Force Survey

1 Both time series are seasonally adjusted.

2 All aged 16 and over.

3 All workers.

though, does have some element of fixed cost, and as a result, may not be an efficient way for employers to react to changes in demand. Oi (1962) discusses the concept of labour being a quasi-fixed factor. Firms generally face costs in adjusting the size of their workforce, such as training, administration and search costs, which constitute an investment by the firm in its labour force (thereby introducing some element of capital in the use of their labour). In the presence of such investment, firms may find it more profitable to reduce hours of work rather than number of jobs (which would constitute a write-off in previous investment). This is sometimes known as labour hoarding and tends to occur when the cost of making staff redundant and then having to recruit later is thought to exceed the current cost of labour, making the decision to keep labour, despite a fall in demand, a rational one. In the short run, a firm is more likely to respond to a shock in the demand for its good or service by adjusting hours worked rather than the number of people employed.

Variation in hours worked is generally viewed as a more responsive indicator of labour demand compared to employment. For example, consider a firm that faces an unexpected increase in the demand for its product. In the short run, in order to meet this increased demand, it may request its workers to work overtime. Statistics on the number of jobs will not capture this change in labour demand, as the number of people employed has remained unchanged. Statistics on hours, however, may capture the change in labour demand by reporting an increase in total hours worked.

\section{Total weekly hours: an overview}

Figure 1 shows total weekly hours of work in the United Kingdom since 1971. This time series is available on a quarterly basis in the Labour Force Survey (LFS) from Q1 1992. Data before this have been estimated from annual data (hence the relatively smooth appearance of the plot when compared to later data). From Q1 (January to March) 1992 to Q1 2008 the total number of hours worked per week shows an upward trend from 833.9 million hours to a peak of 949.2 million hours. The next eight quarters of the time series saw predominantly negative quarter on quarter growth in the total level of hours worked each week, reaching a trough of 909 million hours in the final quarter of 2009, but in the first half of 2010 there was an increase in hours worked per week to stand at 918 million hours.

Figure 1 compares total hours and employment levels over time and shows that the two series are positively correlated. At first glance, the only notable deviation occurs between 2002 and 2007 when the employment level appears to increase faster than the total number of hours worked. However, the hours indicator is actually more responsive to economic downturns.

During the most recent recession, employment recorded a peak to trough fall of 2.3 per cent over the seven quarters between Q2 2008 and Q1 2010. Total hours peaked one quarter before employment in Q1 2008, and over the next seven quarters recorded a peak to trough fall of 4.3 per cent. Larger falls in hours than employment were also features of previous UK recessions in the early 1990s and early 1980s. The peak to trough fall in employment between Q2 1990 and Q1 1993 (11 quarters) was 6.1 per cent whilst the corresponding peak to trough fall in hours between Q4 1989 and Q3 1992 (11 quarters) was 7.5 per cent. Employment peaked in Q4 1979 before falling by 6.4 per cent over the next 14 quarters. Total hours peaked one quarter earlier in Q3 1979 and fell by a larger 10.1 per cent over the following 14 quarters.

\section{Average weekly hours: an overview}

Changes in total hours are the combination of changes in average hours worked by individuals and changes in the number of people in employment.

Figure 2 shows that the average hours worked by individuals has generally seen a downward trend since 1993. This may reflect supply-side developments as people increasingly choose to work fewer hours and due to a rise in the level of part-time working over the timeframe analysed.

Figure 2 also shows that employment has generally trended upward over the period shown. This suggests that, in terms of the total hours worked in the UK economy, 


\section{Figure 3}

Average number of usual weekly hours of work in main job ${ }^{1}$ in the UK and EU272

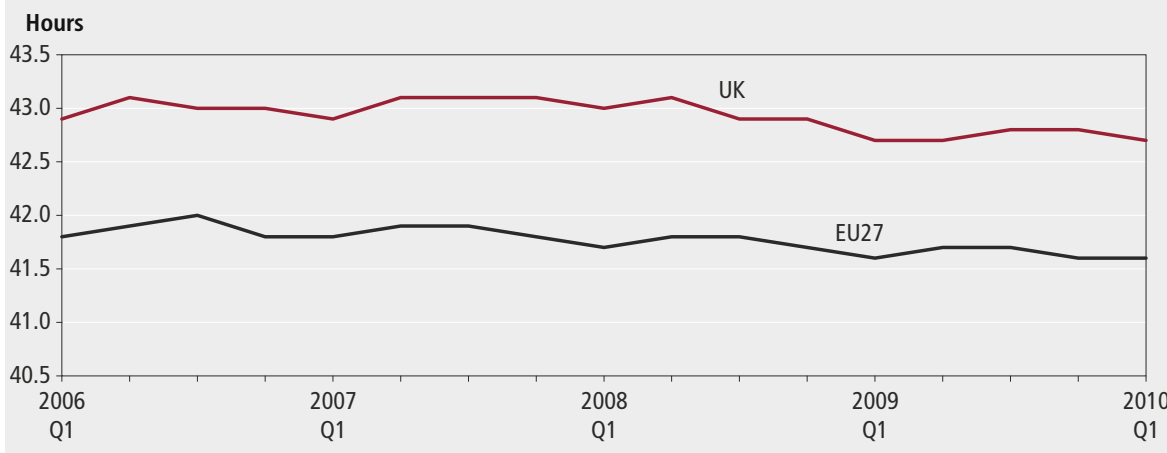

Notes:

Source: Eurostat

1 Full-time workers.

2 EU27 consists of Austria, Belgium, Bulgaria, Cyprus, Czech Republic, Denmark, Estonia, Finland, France, Germany, Greece, Hungary, Ireland, Italy, Latvia, Lithuania, Luxembourg, Malta, Netherlands, Poland, Portugal, Romania, Slovakia, Slovenia, Spain, Sweden and United Kingdom.

3 Eurostat statistics are available online from http://epp.eurostat.ec.europa.eu.

Table 1

\section{Average weekly hours of work by head of household and partner, Q4 20091}

United Kingdom

Percentages

\begin{tabular}{lccrr}
\hline & \multicolumn{4}{c}{ Average hours worked by head of household per week } \\
\cline { 2 - 5 } & $\mathbf{0}$ & $\mathbf{1 - 3 0}$ & $\mathbf{3 1 - 4 0}$ & $\mathbf{4 1 +}$ \\
\hline & & & & \\
Proportion of partners who work zero hours per week & 47.7 & 18.6 & 9.8 & 10.9 \\
Proportion of partners who work 1-30 hours per week & 28.1 & 46.7 & 40.2 & 39.8 \\
Proportion of partners who work 31-40 hours per week & 16.0 & 24.1 & 37.4 & 30.7 \\
Proportion of partners who work 40+ hours per week & 8.2 & 10.6 & 12.6 & 14.8
\end{tabular}

\section{Notes:}

Source: Labour Force Survey

1 Household data are released biannually. Q4 2009 represents the most recent data at the time of writing.

rising employment has been the driver of total hours worked as opposed to average hours.

In 1998 the Working Time Regulation was implemented by the EU to limit working hours to a maximum of 48 hours a week, although individual countries may still choose to establish further limitation on working hours (for example, France has a statutory 35 hour working week). Despite the limitations imposed on working hours; some workers have experienced an increase in the average number of hours worked each week (Böheim and Taylor, 2003; Bishop, 2004). This may be because a proportion of workers choose to voluntarily opt-out of the 48 hour agreement, with approximately a quarter of the UK working population working more than 48 hours per week and nine per cent working more than 60 hours per week (Giga et al, 2008; Barnard et al, 2004).

Bishop (2004) argues that the UK has developed a long working-hours culture in comparison with other EU countries. In 2004,40 per cent of the working labour force in the UK worked in excess of 40 hours a week compared with 10 per cent in Sweden, 16 per cent in France and 20 per cent in Denmark. This may reflect standardised working patterns in many EU countries with the majority of employees working 31 to 40 hours whilst the UK has far less standardised working patterns.

Figure 3 shows that the average number of hours worked in the UK by full-time workers has been consistently higher than the average for the EU. In Q1 2010 the average full-time week was 42.7 hours, compared to 41.6 averaged across the EU.

\section{The relationship between hours worked and household structure}

It is important to consider the household as a whole when analysing labour supply decisions. Antonazzo et al (2003) and Kodz et al (2003) promote the 'unitary' family supply model (which consists of two working age individuals who affect the decisions of each other). Dex et al (1995) studied the average number of working hours within households and found a correlation between the number of hours men worked and the number of hours their partners worked. They concluded that (in a household) if a man worked 'zero' or 'under 31 ' hours per week their partner commonly works 'zero' hours. Similarly if a man worked '31-40' or '41-60' hours per week, their partner commonly works part-time or standard hours ('31-40' per week). Finally, if a man worked ' 41 or more' hours per week 20 per cent of their partners worked '41 or more' hours per week and 31 per cent worked 'zero' hours.

Similar analysis may be conducted using the LFS household dataset. Table 1 shows summary statistics on the proportion of partners who work the same number of hours as the head of household. When the head of the household works zero hours per week, 47.7 per cent of their partners also work zero hours. Similarly when the head of household works 1-30 hours per week, 46.7 per cent of their partners work a similar number of hours. This initially appears to support Dex et al (1995) in finding a positive relationship between the number of hours worked by other members of the household (particularly when considering households who work relatively few hours). As Dex et al (1995) suggest; the relationship may not be as strong as the number of hours worked by the head of the household increases beyond 31 hours per week. In fact when the head of household works 31-40 or $40+$ hours per week their partner tends to work 1-30 hours, with 40.2 per cent and 39.8 percent of partners falling into this category respectively.

Forma (2008) reports that a high workload, problems with a superior and unfavourable work hours put pressure on the relationship between work and family and these factors may contribute to people choosing to withdraw from the workplace. Having children has a significant impact on a worker's decision to work full- or part-time rather than affecting the decision whether to work at all (Antonazzo et al, 2003). The expense of childcare can have a significant impact on labour supply choices, particularly for mothers. If additional hours require extra child care costs then parents may not be willing to work longer hours (Böheim and Taylor, 2003; Powell, 2000).

Kodz et al (2003) found that men with children were more likely to work long hours whilst women with children were more likely to work fewer.

Table 2 shows that this remains the case in the UK. In the four quarters up to and including Q2 2010, full-time males with dependent children tended to work 0.9 hours per week more than males with no 
Table 2

Average weekly hours of work by sex and whether dependent child in household, 2009-10'

\begin{tabular}{|c|c|c|c|}
\hline \multicolumn{2}{|c|}{ United Kingdom } & & \multirow[t]{2}{*}{ Hours } \\
\hline & & Average weekly hours of work & \\
\hline & & Full time & Part time \\
\hline \multirow[t]{2}{*}{ Male } & Without dependent child & 38.8 & 16.9 \\
\hline & With dependent child & 39.6 & 15.9 \\
\hline \multirow[t]{2}{*}{ Female } & Without dependent child & 35.2 & 16.5 \\
\hline & With dependent child & 31.4 & 15.8 \\
\hline
\end{tabular}

Notes:

Source: Labour Force Survey

1 Four quarter average (Q3 2009-Q2 2010).

\section{Figure 4}

\section{GfK Consumer Confidence index ${ }^{1}$ and annual change in total average} hours worked, ${ }^{2}$ 1982-2010

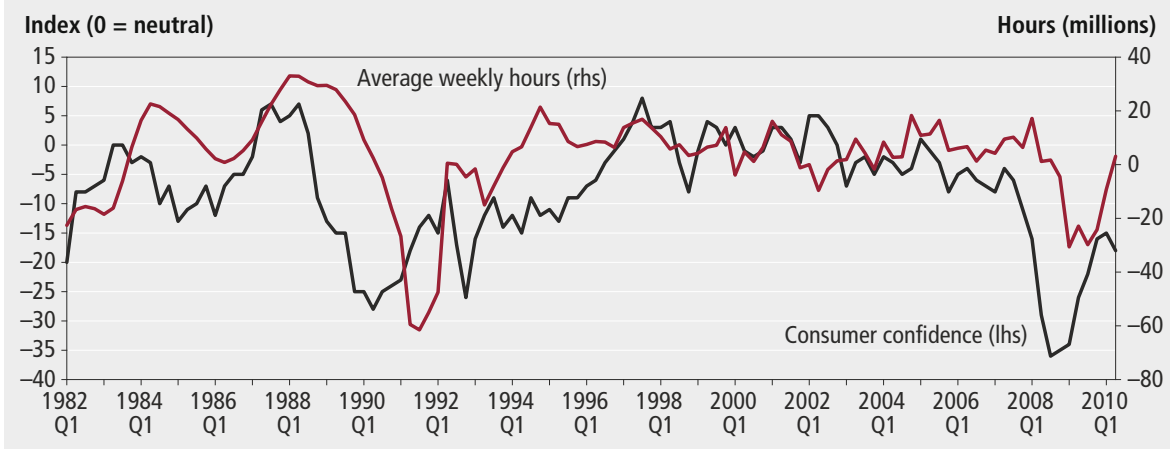

\section{Notes:}

Source: Labour Force Survey and GfK Consumer Confidence Barometer

1 GfK data are not seasonally adjusted.

2 LFS data are seasonally adjusted. dependent children. Full-time working females with dependent children, however, tended to work 3.8 hours per week less than females with no dependent children. The story is not so apparent when considering part time workers who tend to work fewer hours per week if they have a dependent child in the household (regardless of sex).

\section{The relationship between hours, consumer confidence and GDP}

In the 2008-09 recession, employment did not fall as much as in previous recessions ${ }^{1}$.

One explanation is that employers may have been able to reduce the volume of hours and increase the use of parttime working rather than make workers redundant (see Eurostat, 2009). Over the course of this latest recession, the actual number of hours worked across the EU fell. Across the $27 \mathrm{EU}$ member countries, hours worked per week fell, on average, by 0.7 hours between Q2 2008 and Q2 2009. In the UK, actual hours worked fell by 0.4 hours to 40.8 hours a week (Eurostat, 2009).

A weak labour market in times of recession typically results in less job security, greater fear of redundancy and is affected by uncertainty over future wages. This is corroborated by Flodén, (2005) who analyses the US self-employed labour market and confirms that people work longer hours in times of uncertainty.

Having said that, the number of hours an employee is expected to work may be constrained by the employer. If there are many jobs available, workers still have the opportunity to choose the job (or jobs) with the most desirable hours at a given wage. The more restricted the market is, the less choices a worker has (Dickens and Lundburg, 1993). This is the case in times of recession, when (due to labour demand constraints) employers may choose to reduce staff headcount, or reduce working hours. The combination of employees wishing to work longer hours lead to workers becoming under-employed or even unemployed.

Figure 4 plots the annual change in total hours of work and the level of consumer confidence (as measured by GfK NOP Limited $^{2}$ ). If workers prefer to work longer hours in times of uncertainty then an inverse relationship between the number of hours supplied by workers and the level of consumer confidence might be expected. This is not entirely supported by the data in Figure 4. The relationship between consumer confidence and the change in total hours is complex and largely inconclusive (showing periods of both positive and negative correlation). This may reflect the relevance of other theories arguing for pro-cyclical labour supply ${ }^{3}$, and that lags between household confidence indicators and labour supply decisions make the relationship hard to identify.

As the demand for labour is derived from the goods and services produced and employers wishing to reduce hours can

\section{Figure 5}

Year on year growth rates for output and total actual hours worked, 1972-2010

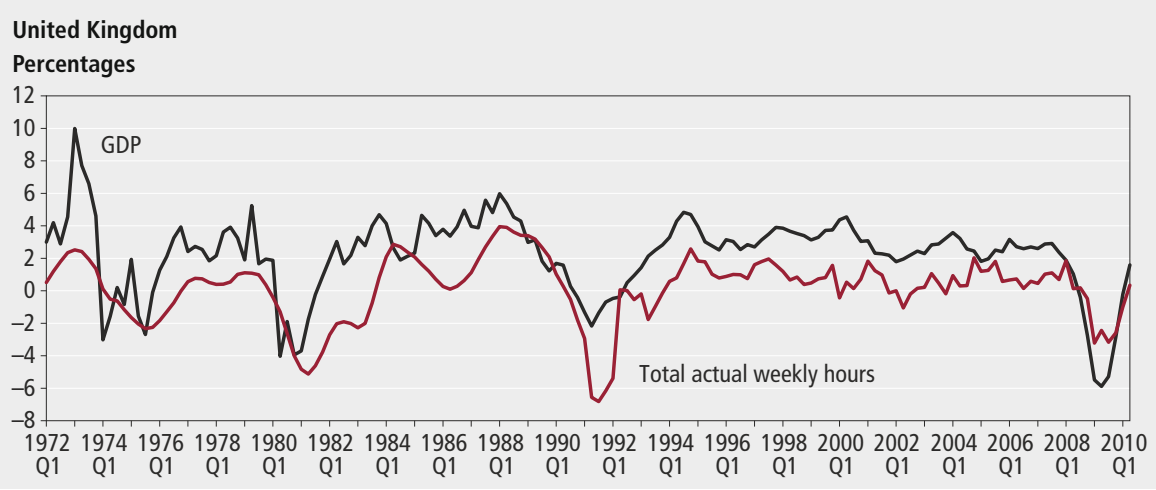

1 Both series are seasonally adjusted 
by firms a positive relationship between output and labour inputs is expected.

Figure 5 plots year on year growth rates for total hours of work and UK gross domestic product (GDP) and shows changes in the level of hours worked in the UK follow a cyclical pattern. Total weekly hours worked are positively correlated (to a degree of 0.7) with the annual growth in GDP. Total weekly hours worked reached a peak in Q1 2008 at 949.2 million hours before falling consistently through the recession to 908.6 million hours in Q4 2009 , the lowest number of total hours worked in the UK economy since 2003. The positive relationship between hours worked and the state of the economy shown in Figure 4 and Figure 5 suggests that the economy's influence on labour demand is stronger than its influence on labour supply.

\section{Conclusion}

The number of hours worked in the economy results from a combination of decisions by individuals about how many hours of labour to supply, and decisions by firms about how many hours of labour to demand. This article has shown that hours worked is an important indicator and is a more responsive measure of the state of the labour market than employment, both in terms of timeliness and variation. The article also presents some evidence of a long working-hours culture in the UK when compared to the average across the EU. This is despite a general falling trend in the average number of hours worked each week since 1992.

The decision to supply labour is found to be influenced by the composition of household. The number of hours worked is correlated with the number of hours an individual's partner works. This is especially true when the head of the household works no (zero) hours. When considering the prevailing state of the economy, it is likely to be labour demand (from firms) which influences the total number of hours worked. The analysis showed that during periods of recession the total actual weekly hours fell. The main cause of this is likely to be the reaction of firms to falling demand.
Individuals may be willing to supply more labour to help protect against uncertainty but this influence is not found to be as strong as the cyclical impact on labour demand.

\section{Notes}

1. For a comparison of UK unemployment over recessions see www.statistics.gov. uk/cci/nugget.asp?id=2294

2. The GfK NOP Consumer Confidence Index is an overall measure of consumer confidence. Further information is available from www. gfknop.com/pressinfo/keysurveys/ index.en.html

3. For example, Real Business Cycle theory argues that pro-cyclical movements in real wages induce the same pro-cyclical pattern in labour supply by encouraging individuals to substitute leisure for labour when the economy is strong and vice-versa when the economy is weak.

\section{CONTACT}

(网elmr@ons.gsi.gov.uk

\section{REFERENCES}

Adams J (1963) 'Toward an Understanding of Inequity', Journal of Abnormal and Social Psychology vol 67, pp 422-436

Antonazzo E, Scott A, Skatun D and Elliott $R$ (2003) 'The labour market for nursing: a review of the labour supply literature', Health Economics vol 12, pp 465-478

Barnard C, Deakin S and Hobbs R (2004)

'Opting out of the 48 hour week - Employer necessity or individual choice?' Working Paper No. 282, ESCE Centre for Business Research, University of Cambridge

Bishop K (2004) 'Working time patterns in the UK, France, Denmark and Sweden', Labour Market Trends, Office for National Statistics, March 2004

Böheim R and Taylor M (2003) 'Option or obligation? The determinants of labour supply preferences in Britain', ISER working paper No. 2001-05. Institute for Social and Economic Research
Dex S, Clark A and Taylor M (1995)

'Household Labour Supply'. DoE Research Series 43. ESRC Research Centre on Microsocial Change, University of Essex

Dickens W and Lundburg S (1993) 'Hours Restrictions and Labor Supply', International Economic Review vol 34, No 1

Eurostat (2009) 'Labour market and the economic crisis: Fewer hours worked and more part-time in EU27', Eurostat News Release, Issue 159/2009

Flodén M. (2005) 'Labour Supply and Savings under Uncertainty', SSE/EFI Working Paper Series in Economics and Finance. No 597

Forma P (2008) 'Work, family and intentions to withdraw from the workplace' International Journal of Social Welfare vol 18 pp 183-192

Giga S, Jain A and Cooper C (2008) 'Working Longer: Hours of Work and Health', State-ofScience Review SR-C7, Government Office for Science

Kodz J, Davis S, Lain D, Strebler M, Rick J, Bates P, Cummings J and Meager N (2003) 'Working long hours: a review of the evidence', Employment Relations Research Series No.16, Department of Trade and Industry

Oi W (1962) 'Labor as a quasi-fixed factor'. Journal of Political Economy, vol 70, no 6.

Parker S, Belghitar Y and Barmby T (2005) 'Wage Uncertainty and the Labour Supply of Self-Employed Workers', Economic Journal vol 115, Issue 502, Pages C190-C207

Powell L (2000) 'Joint Labour Supply and Childcare Choice Decisions of Married Mothers', The Journal of Human Resources, vol 37, pp 106-128

Spurgeon A (2003) 'Working time: Its impact on safety and health', International Labour Office. Available from:

www.ilo.org/public/english/protection/ condtrav/publ/wtwo-as-03.htm

Tam H (2010) 'Characteristics of the underemployed and the overemployed in the UK', Economic \& Labour Market Review, July 2010, vol 4, no 7, pp 36-44 